\title{
Realization of Peptone Biosensor Based on Newly Prepared NiO Nanostructures
}

\author{
Sumbul Saeed ${ }^{1}$, Muhammad Rafiq ${ }^{1}$, Qurrat-ul-Ain Baloach², Syed Habib Ahmed Naqvi ${ }^{1}$, \\ Aneela Tahira ${ }^{5}$, Magnus Willander ${ }^{3}$, Mansoor Akhtar $^{4}$, and Zafar Hussain Ibupoto ${ }^{2,5, *}$ \\ 1 Institute of Biotechnology and Genetic Engineering, University of Sindh-76080, Jamshoro, Pakistan \\ ${ }^{2}$ Dr. M. A. Kazi Institute of Chemistry University of Sindh-76080, Jamshoro, Pakistan \\ ${ }^{3}$ Department of Science and Technology, Campus Norrkoping, Linkoping University, SE-60174, Norrkoping, Sweden \\ ${ }^{4}$ Key Lab of Polyoxometalate of Science, Northeast Normal University, Changchun City, Jilin Province, P. R. China \\ ${ }^{5}$ Division of Material Science, Dept. of Engineering and Mathematics, Lulea University of Technology, Lulea, Sweden
}

(Received: xx Xxxx xxxx. Accepted: xx Xxxx xxxx)

\begin{abstract}
The present study authenticates the fabrication of nickel oxide porous shaped nanostructure by hydrothermal method. The novel and functionalized nickel oxide nanomaterial were visualized by using scanning electron microscopy (SEM) and X-ray diffraction techniques (XRD). NiO nanomaterial advertised sensitive, selective and attracted morphology for the development of peptone biosensor. Phenylalanine displays a soft template and growth directing agent for the developing of nickel oxide low dimension nanostructures. The nickel oxide nanomaterial together with protease possesses tremendous role towards the oxidation potential phenomena and transfer of anodic electrocatalytic current for the peptone. The generation of low potential electrochemical signals exhibited the determination of peptone by utilizing different electrochemical techniques for the given concentration ranging from $0.1 \mathrm{mM}$ to $2.5 \mathrm{mM}$ with the measured limit of detection about $0.002 \mathrm{mM}$ with a sensitivity of $107200 \mu \mathrm{A} / \mathrm{mMCm}^{2}$. The well-defined and highly developed sensor system provides the standard platform for the fabrication and functioning of new devices that are helpful for the determination of many biological macromolecules. The presented peptone biosensor is highly selective, sensitive, and reproducible that could also be useful for the determination of peptone from various milk samples.
\end{abstract}

Keywords: Nickel Oxide (NiO) Nanostructure, Protease Enzyme, Peptone, Phenylalanine Nanomaterials, Differential Pulse Voltammetry.

\section{INTRODUCTION}

Peptones are the hydrolysis product of proteins and polypeptides and are soluble in water and not coagulable by heat. ${ }^{1}$ Peptones is the most expensive nitrogenous source used for bacterial growth purpose, as far as the present study is concerned it is obtained from plants, ${ }^{2}$ casein (milk protein) as a dairy product ${ }^{3}$ and also from whey. ${ }^{4}$ The primarily source of peptone is bovine but it is also chiefly synthesized from other sources like gelatin, milk, meat, and also obtained from plants and microorganisms. ${ }^{5}$

Enzymes are the important biological catalyst other than chemical catalyst that plays a tremendous role and take active part in all metabolic and biochemical pathways. In many purposes, enzymes possess a special attention towards industrial point of view as they play an active

${ }^{*}$ Corresponding author; E-mail: zaffar_ibupoto@yahoo.com part as an organic catalyst. Majority of the enzymes that are isolated from microbial sources has been utilized in many commercial purposes. The selection of microorganisms including bacteria, fungi, and yeast has been studied and widely utilized for the synthesis and selection of various enzymes that increase the productivity at commercial scale. ${ }^{6}$ Among them microbial proteases are thought to be one of the largest group of enzymes including hydrolytic that are commercially accepted as the most economically-applicable enzyme. ${ }^{7-12}$ Enzymes plays the most active and beneficial part in many biotechnological applications ${ }^{13}$ and are being utilized in variety of fields such as in dairy processes, baking, brewing, leather, detergent, pulp, dietary supplements and paper industries. ${ }^{14-17}$ The protease enzymes possess a special attention due to its unique property to hydrolysates proteins into poly peptidases, proteinases and peptide bonds respectively. As well 
as the present research is concerned, protease enzyme is isolated for the development of peptones biosensors.

Biosensor is a device that utilizes specific recognition equipment to sense the biologically active compounds or macromolecules. Specifically biosensor based on three active components;

(1) detector, which sense the analyte;

(2) transducer, that converts the sensing analyte into a detectable signals;

(3) the display device, which consists of amplifier that convey the signals and display onto the screen in a measureable way. ${ }^{18}$

The use of nanoparticles (NPs) in biosensors gives a new concept in the field of research and many reported have been published related to the immobilization of nanoparticles with the sensing parameters. ${ }^{19-22}$

Electrochemical transducer possesses beneficial and reliable properties in biosensing technology $y^{23}$ because have capacity to fast response, high sensitivity, low cast, rapidity, portability, and including them have capacity to sense even a micro analyte in sample. More interestingly, provide a specific and reliable platform for the immobilization of biomolecule that incorporates with electrically based devices, with less susceptible chance of contamination as compare to other analytical devices. ${ }^{24}$

A novel, and new era of research is emerging from the compiling and combination with various disciplines of biologically derived subjects including physics, chemistry, biotechnology and so on, called as "nanotechnology" this term is used for the synthesis procedure of nanostructure even in nano or micro size range. The technique "nanoscience" is concerned with those objects that are somehow measureable range in between 1 to $100 \mathrm{~nm} .{ }^{25}$ With the advancement of nanotechnology, nanomaterials exhibit tremendous role all around because have fast response towards electrical, optical, and electro catalytic property. Comparing with many nanoparticles, nickel oxide $(\mathrm{NiO})$ nanostructure exhibit a definite structure and size and have tremendous and wide spread applications including magnetic, electro chromic, ceramic, designing and catalytic substances. ${ }^{26}$

Many processes have been employed for the fabrication of $\mathrm{NiO}$ nanomaterial consisted of sol-gel, ${ }^{27}$ surfactant mediated synthesis, ${ }^{28}$ thermal decomposition ${ }^{29}$ and polymer matrix assisted preparation. ${ }^{30}$ Generally, it can be seen that the hydrothermal procedure is simple, inexpensive, gives high yield of desired products and also very useful for commercial point of view. Till now, various protocols have been adopted for the fabrication of $\mathrm{NiO}$ nanostructures and nanorods, among them only few methods have been reported and published for the fabrication of $\mathrm{NiO}$ nano platform. ${ }^{31,32}$

Up to now, no any report suggested the significance and advantages of phenylalanine, that works as a growth directing, soft template, and acts as a modifier for the synthesis of nickel oxide nanostructure and till now and no any single biosensor is introduced for the quantification of peptone. This is one of the newly developed sensors in the field of nanotechnology that sense the presence of milk and other in a given sample.

In this research, newly synthesized nanoparticles of nickel oxide were fabricated with phenylalanine that acts as a growth directing modifier for the structural determination using hydrothermal procedure. The structural characterization of nickel oxide nanomaterial was studied by SEM and XRD techniques. For the development of peptone biosensor, nickel oxide nanoparticles were functionalized with protease enzyme for the determination of peptone from milk and other dairy products.

\section{MATERIALS AND METHODS}

\subsection{Chemicals}

Nickel nitrate hexahydrate $\left(\mathrm{NiNO}_{3} \cdot 6 \mathrm{H}_{2} \mathrm{O}\right)$, ammonia, phenylalanine, peptone, gelatin, albumin, casein, lysine, glycine, glucose, melamine, salts of sodium and potassium, urea, ammonium sulfate, potassium dihydrogen phosphate, calcium chloride dehydrated, calcium chloride hexahydrate, magnesium sulphate heptahydrate, iron (ii) sulfate heptahydrate, twean 80, manganese sulfate heptahydrate and zinc sulfate heptahydrate were purchased from Sigma Aldrich and MERCK. For the preparation of all solutions the phosphate buffer $(\mathrm{pH} 7.4)$ was used.

\subsection{Fabrication of $\mathrm{NiO}$ Nanostructure}

For the synthesis of nickel oxide nanomaterial hydrothermal method was followed. ${ }^{37}$ First, reaction mixture was prepared by the amalgamation of $0.1 \mathrm{M}$ nickel nitrate, $5.0 \mathrm{ml}$ ammonia, and $0.5 \mathrm{~g}$ of phenylalanine in a beaker containing $100 \mathrm{ml}$ deionized water and mixed properly and placed in preheated electric oven at $95{ }^{\circ} \mathrm{C}$ for $5 \mathrm{~h}$. After the completion of synthesis procedure, the beaker was put at room temperature till it became cool, and then collected the precipitates with the help of Whattman filter paper. The $\mathrm{Ni}(\mathrm{OH})_{2}$ nanomaterial was then placed in preheated electric furnace at $450{ }^{\circ} \mathrm{C}$ put for $3 \mathrm{~h}$ for the complete conversion of hydroxide oxide phase to pure oxide phase. The morphological and structural characterization of $\mathrm{NiO}$ nanomaterials was performed by scanning electron microscope (SEM) at $5 \mathrm{KV}$ and $\mathrm{X}$-ray diffraction technique (XRD) by using a powder made by Phillips PW 1729 with the help of diffractrometer, the working performance is monitored by emitting radiation of $\mathrm{CuKa}(1=1.5418)$ with the help of equipped generator working at constant voltage of $40 \mathrm{KV}$ at applied current $40 \mathrm{~mA}$ respectively.

\subsection{Immobilization of Protease on $\mathrm{NiO}$ Nanoparticles and Their Electrochemical Applications for the Detection of Peptone}

For the applications of protease enzyme immobilized on $\mathrm{NiO}$ nanoparticles, certain modified glassy coated carbon electrodes were used. ${ }^{37} 0.5 \mathrm{~g}$ peptone was mixed in 
phosphate buffer solution and finally made volume up to $1.0 \mathrm{mM}$ peptone. $5.0 \mathrm{mg}$ of synthesized nickel oxide nanoparticles were taken and carefully dissolved in deionized water, sonicated for 20 mints and then mixed with $0.5 \mathrm{ml}$ protease enzyme solution $(5.0 \mathrm{mg}$ per $\mathrm{ml}$ of phosphate buffer). A clean glassy carbon electrode was used as working electrode by depositing $\mathrm{NiO}$ nanostructures functionalized with protease by drop casting method. About $5 \mu \mathrm{l}$ of nanostructures suspension was dropped on the glassy carbon electrode, consequently $5 \%$ Nafin was also dropped on $\mathrm{NiO}$ nanostructures in order to prevent the loss of material from the surface of electrode during the measurement. Then the modified electrode was left to dry at room temperature. The electrochemical techniques were adapted for the quantification of peptone at room temperature.

\section{RESULTS AND DISCUSSION}

\subsection{The Structural Characterization of NiO Nanostructure}

The shape exposure of newly fabricated nickel oxide nanostructure was elucidated by scanning electron microscope. The magnified SEM images showed porous like structure of $\mathrm{NiO}$ as illustrated in Figure 1. The phenyl alanine resulted a new shape of $\mathrm{NiO}$ with improved catalytic properties which are proved by the development of peptone biosensor. Herein phenyl alanine plays a key role in shaping the nanostructures of $\mathrm{NiO}$ as a soft template and growth orientating alignments due to its unique chemical structure which contains amine and carboxylic along with phenyl group. These features of phenylalanine are responsible in the evolution of morphology of $\mathrm{NiO}$ in the present case study. The unique properties of synthesized nickel oxide nanostructure have proved to be a strong and motivating nanomaterial, and it is the first electrochemical biosensor for the determination of protein in complex system. There is high matching of enzyme protease with the fabricated $\mathrm{NiO}$ nanostructures which can bind strongly and finally giving a birth to the development novel analytical device by sensing peptone. The crystal structure of $\mathrm{NiO}$ was evaluated by XRD and obtained diffractions are according standard data base (JCPDS card no: 45-1027) as shown in Figure 2.

\subsection{Measurement of Electrical Signal from the Functionalized NiO Nanostructures with Protease Enzyme}

Electrochemical response was found when protease together with synthesized nickel oxide nanoparticles was deposited on GCE (glassy carbon electrode) and the measured results of peptone are realized through
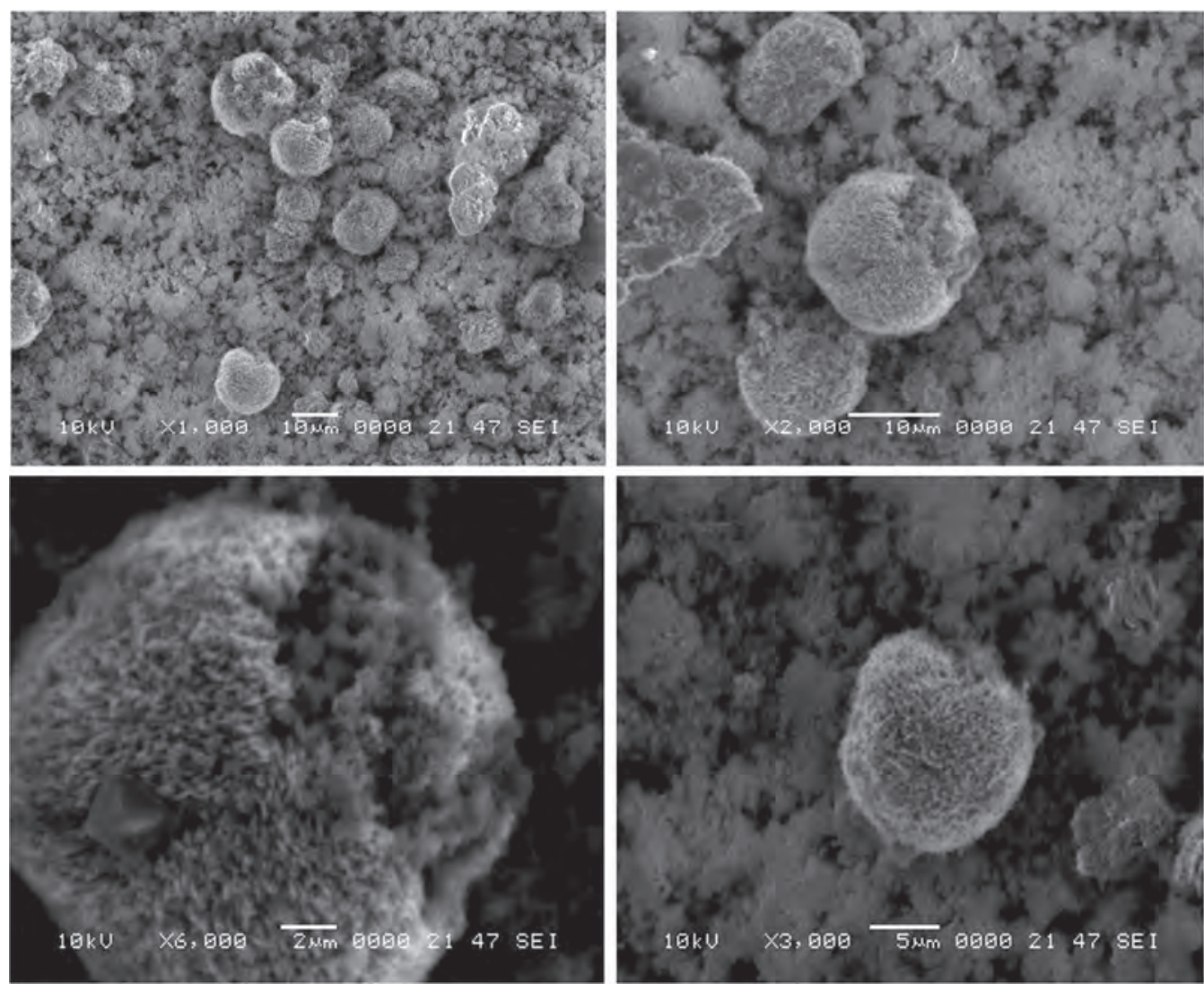

Fig. 1. SEM images of $\mathrm{NiO}$ nanostructures obtained in the presence of phenyl alanine at different magnifications. 


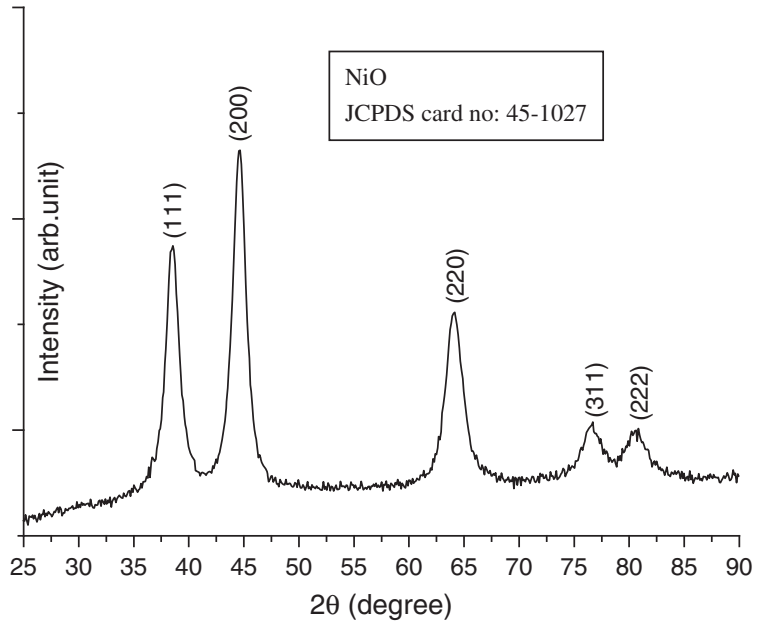

Fig. 2. XRD image of the synthesized $\mathrm{NiO}$ nanostructure.

voltammetry (CV). The CV response was monitored at different concentrations followed with bare and modified electrodes in the presence or absence of peptone that works as standard analyte.

The CV was performed in a blank solution containing phosphate buffer with adjustable $\mathrm{pH} 7.4$ and peptone $(1 \mathrm{mM})$ a steady current was achieved at $50 \mathrm{mV} / \mathrm{S}$. In Figure 3(a) showed no signal for bare electrode was found, (b) however the bare glassy carbon electrode did not show even response in the solution of peptone, a small rise in anodic peak is found when modified electrode was immersed in phosphate buffer solution as shown in (c), however, a significant and quantifiable signal is achieved by $\mathrm{NiO}$ nanostructures modified for the sensing of peptone as depicted in Figure 3(d). The sensitivity and selectivity was also obtained through differential pulse voltammetry, the following response was evaluated for the determination of peptone in the peptone analyte. The differential pulse voltammetry was used for the measuring the electrical signal for various concentrations of peptone in ranging from $0.1 \mathrm{mM}, 1 \mathrm{mM}, 1.5 \mathrm{mM}, 2 \mathrm{mM}, 2.5 \mathrm{mM}, 3 \mathrm{mM}$

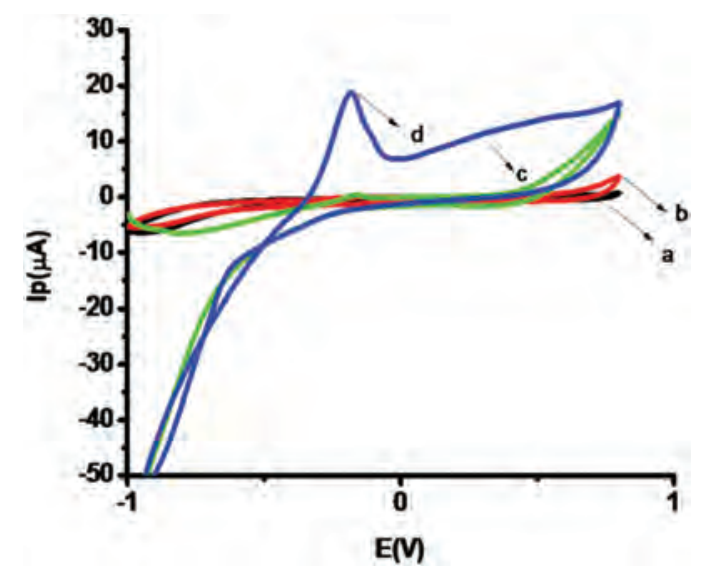

Fig. 3. The cyclic voltammetry response for bare and protease immobilized $\mathrm{NiO}$ porous structures in the absence and presence of peptone.
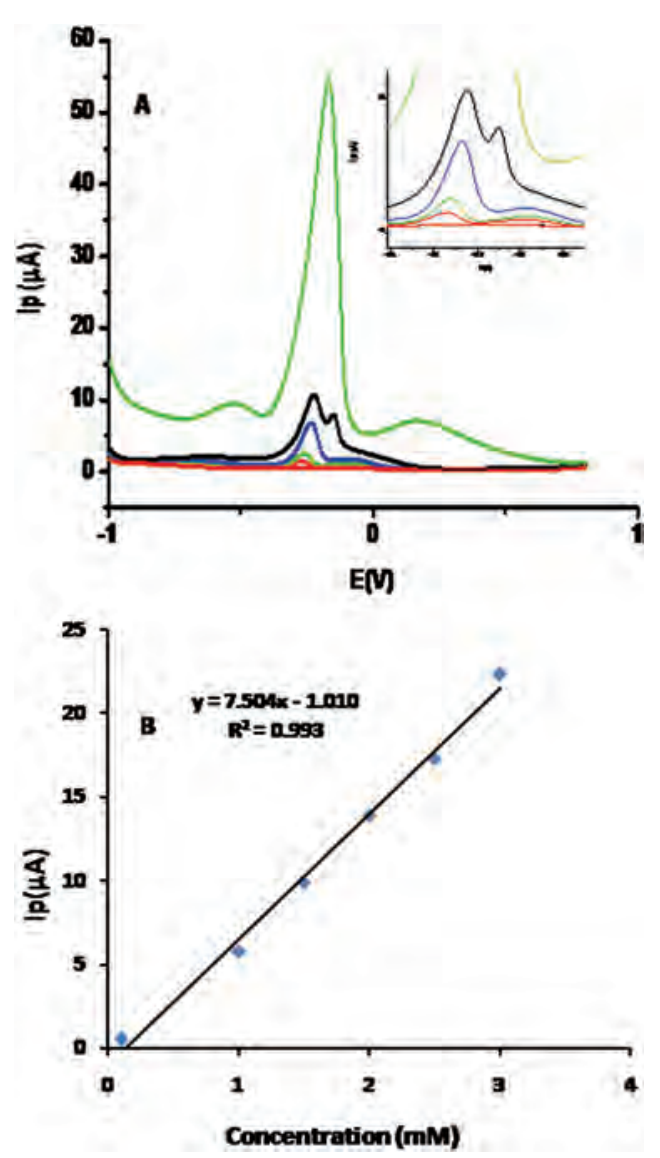

Fig. 4. (A) Differential pulse voltammetry signals of developed electrode for different concentrations of peptone. (B) The linear plot achieved by fitting peak current versus concentration of peptone.

respectively as shown Figure 4(a). A calibration graph was obtained by plotting the measured current against respective concentration of peptone which demonstrated a linear response as shown in Figure 4(b). This showed explicitly that the oxidation potential of peptone was obtained when incorporated with nickel oxide nanomaterial possesses high surface to volume ratio and also capable to enhance the electro catalytic properties for rapid transfer of electrons that generated a suitable electrical signals. The presented protease enzyme being focus is the part of present study. The calculated (LOD) limit of detection for the developed peptone biosensor is $0.002202 \mathrm{mM}$

Table I. The storage stability of biosensor for six weeks.

\begin{tabular}{lccc}
\hline $\begin{array}{l}\text { Number of } \\
\text { weeks }\end{array}$ & $\begin{array}{c}\text { Linear range } \\
(\mathrm{mM})\end{array}$ & $\begin{array}{c}\text { Limit of } \\
\text { detection }(\mathrm{mM})\end{array}$ & $\begin{array}{c}\text { Sensitivity } \\
\left(\mu \mathrm{A} / \mathrm{mM} / \mathrm{Cm}^{-2}\right)\end{array}$ \\
\hline 1 & $0.1-3$ & 0.002 & 107200 \\
2 & $0.1-3$ & 0.001 & 107200 \\
3 & $0.1-3$ & 0.002 & 107200 \\
4 & $0.1-3$ & 0.003 & 107200 \\
5 & $0.1-3$ & 0.002 & 107200 \\
6 & $0.1-2.85$ & 0.001 & 107200 \\
\hline
\end{tabular}


Table II. Analytical application of peptone in milk sample.

\begin{tabular}{lccc}
\hline Sample & Added $(\mathrm{mM})$ & Found $(\mathrm{mM})$ & \% Recovery \\
\hline 1 & 0.1 & 0.11 & 110 \\
2 & 0.2 & 0.22 & 110 \\
3 & 0.3 & 0.29 & 96 \\
4 & 0.4 & 0.43 & 107 \\
\hline
\end{tabular}

and its sensitivity was evaluated as $107200 \mu \mathrm{A} / \mathrm{mM} / \mathrm{Cm}^{-2}$ respectively.

The selectivity response of peptone biosensor based on $\mathrm{NiO}$ nanostructures was evaluated in the presence of commonly coexisting species such as casein, albumin, melamine and glucose in $0.1 \mathrm{mM}$ peptone solution. The concentration of each interfering species was 10 times higher than peptone and the response of biosensor towards these compounds was negligible which can be attributed to the selective response of protease enzyme only towards peptone oxidation.

The storage stability of presented peptone biosensor based on $\mathrm{NiO}$ nanostructures was monitored for the period of six weeks and the evaluating parameters such as linear range, limit of detection and sensitivity were studied as given in Table I. As it can be seen that the biosensor response is highly stable and there is negligible loss of linear range and limit of detection, however the sensitivity remained unaltered throughout study. The biosensor was kept at $4{ }^{\circ} \mathrm{C}$ when not in use.

\subsection{The Analytical Application of Peptone Biosensor}

The analytical application of peptone biosensor based on $\mathrm{NiO}$ was performed by monitoring the peptone level in milk samples. The samples were prepared according to the published work. ${ }^{38}$ The obtained results are enclosed in Table II. Due to very low concentration of peptone in the milk samples which was not responded by the biosensor so recovery method was used to accomplish this study by spiking the standard concentrations of peptone in milk samples. The satisfactory response was found with reliable percent recoveries which highlights the practicality of the presented peptone biosensor.

\section{CONCLUSIONS}

The present work displays the newly advanced and highly developed strategy for the evaluation of peptone using phosphate buffer. The sensor study accounts the utilization of functionalized and highly developed $\mathrm{NiO}$ nanostructure for the fabrication of low anodic current for the linear concentration ranging from $0.1 \mathrm{mM}$ to $3 \mathrm{mM}$. The present study displays that the phenylalanine as a modifier and a growth directing agent. XRD and SEM both techniques demonstrates the nickel oxide porous nanostructure. $\mathrm{NiO}$ nanostructures are successfully utilized for the development of peptone biosensor which is for the first time is realized.

\section{References and Notes}

1. J. H. Green, S. L. Paskell, and D. Goldmintz, J. Food Protect 40, 181 (1977).

2. J. Parrado, F. Millan, I. Hernandez-Pinzon, J. Bautista, and A. Machado, Process Biochemistry 28, 109 (1993).

3. R. Reissbrodt, W. Beer, R. Muller, and H. Claus, Acta Biotechnol. 15, 223 (1995).

4. B. Lund, B. Norddahl, and B. Hring, Biotechnol Lett. 14, 851 (1992)

5. E. Y. Blidson, A. Brecker, and N. A. Ribbons, Academic Press, New York (1970), p. 230.

6. A. Pandey, P. Selvakumar, C. R. Soccol, and P. Nigam, Curr. Sci. 77, 149 (1999).

7. A. K. Mukherjee, H. Adhikari, and S. K. Rai, J. Biochem. Eng. 39, 353 (2008).

8. R. N. Rahman, M. Basri, and A. B. Salleh, Ann. Microbiol. 53, 1999 (2003).

9. C. J. Chudasama, S. A. Jani, H. M. Jajda, and H. N. Pate, J. Cell Tissue Res. 10, 2257 (2010).

10. H. Genckal and C. Tari, Enzym. Microb. Technol. 39, 703 (2006).

11. R. Gupta, Q. K. Beg, and P. Lorenz, Appl. Microbiol. Biotechnol. 59,15 (2002)

12. S. Vijayalakshmi, S. V. Kumar, and V. Thankamani, Res. J. Biotechnol. 6, 26 (2011).

13. J. Norus, European Planning Studies 14, 681 (2006).

14. P. Binod, R. R. Singhania, C. R. Soccol, and A. Pandey, Asiatech Publishers, India (2008), p. 291.

15. R. M. Berka and J. R. Cherry, C. Ratledge, and B. Kristiansen (eds.), Cambridge University Press, Cambridge, UK (2006), p. 477.

16. O. Kirk, T. V. Borchert, and C. C. Fuglsang, Current Opinion in Biotechnology 13, 345 (2002).

17. T. Schafer, T. W. Borchert, V. S. Nielsen, et al., Advances in Biochemical Engineering/Biotechnology 105, 59 (2006).

18. A. F. Collings and F. Caruso, Rep. Prog. Phys. 60, 1397 (1997).

19. M. Souiri, L. Mora-Ponsonnet, K. Glinel, A. Othmane, T. Jouenne, and A. C. Duncan, Colloids and Surfaces B; Biointerfaces 68, 125 (2009).

20. A. Merkoci, Anal. Chem. 81, 519 (2009).

21. K. Balasubramanian and M. Burghard, Anal. Bioanal. Chem. 385,452 (2006)

22. O. A. Sadik, A. O. Aluoch, and A. Zhou, Biosens. Bioelectron. 24, 2749 (2009).

23. A. Bratov and N. Abramova, D. E. Suarez, Nova Science Publishers (2013), p. 155.

24. I. Palchetti and M. Mascini, Anal. Bioanal. Chem. 391, 455 (2008).

25. E. S. Kawasaki and A. Player, Nanomedicine: Nanotechnology, Biology and Medicine 1, 101 (2005).

26. D. Tao and F. Wei, Mater. Lett. 58, 3226 (2004)

27. K. C. Liu and M. A. Anderson, Journal of the Electrochemical Society 143,124 (1996)

28. Y. D. Wang, C. L. Ma, X. D. Sun, and H. D. Li, Inorganic Chemistry Communications 2, 751 (2002).

29. L. Xiang, X. Y. Deng, and Y. Jin, Scripta Materialia 47, 219 (2002).

30. S. Deki, H. Yanagimito, and S. Hiraoka, Chem. Mater. 15, 4916 (2003)

31. B. Cheng, Y. Le, W. Q. Cai, and J. G. Yu, Journal of Hazardous Materials 185, 889 (2010)

32. M. Villagran, J. Costamagna, and J. H. Zagal, Journal of Coordination Chemistry 59, 1467 (2006).

33. J. H. Warcup, Nature 166, 117 (1950).

34. R. G. Burrel, C. W. Clayton, M. F. Gallegly, and V. D. Lilly, Phytopathology 56, 422 (1966).

35. B. Schwermann, K. Pfau, B. Liliensiek, M. Schleyer, T. Fischer, and E. P. Baker, Eur. J. Biochem. 226, 981 (1994).

36. D. Penner and F. M. Ashton, Plant Physiology 42, 791 (1967).

37. Z. H. Ibupoto, S. Elhag, M. S. AlSalhi, O. Nur, and M. Willander, Electroanalysis 26, 1773 (2014).

38. Q. Cao, H. Zhao, L. Zeng, J. Wang, R. Wang, X. Qiu, and Y. He, Talanta 80, 484 (2009). 